\title{
Período de Descanso, Características Estruturais do Dossel e Ganho de Peso Vivo de Novilhos em Pastagem de Capim-Mombaça sob Lotação Intermitente ${ }^{1}$
}

\author{
Emerson Alexandrino², Carlos Augusto Miranda Gomide ${ }^{3}$, Magno José Duarte Cândido ${ }^{4}$, \\ José Alberto Gomide ${ }^{5}$
}

\begin{abstract}
RESUMO - Em pastagem de capim Panicum maximum cv. Mombaça, avaliou-se o efeito de dois períodos de descanso, definidos pelo tempo necessário para a expansão de 2,5 e 3,5 novas folhas/perfilho, sobre as características estruturais do dossel - altura, massa de forragem verde, de folha verde ede colmo, relação folha/colmo e índice de área foliar (IAF) - e a produção animal. Realizou-se, ainda, o acompanhamento do efeito do momento de pastejo (entrada e saída dos animais) e dos ciclos de pastejo (1ํㅜ , 2o e $3 \underline{0}$ ciclos) sobre a evolução das características do dossel e sobre a oferta de forragem (OF). A área experimental foi dividida em seis e sete piquetes para os tratamentos 2,5 e 3,5 novas folhas, respectivamente. Os tratamentos foram dispostos em delineamento inteiramente casualizado, com duas repetições. Os períodos de descanso estudados interagiram com os ciclos e os momentos de pastejo, mas não tiveram efeito sobre as características estruturais do dossel, à exceção da relação folha/colmo, que foi mais larga nos piquetes sob o menor período de descanso somente no momento de entrada dos animais nos piquetes, comprovando efeito negativo dos períodos de descanso sobre essa variável. As características estruturais cresceram com a sucessão dos ciclos de pastejo, de modo que os valores mais altos corresponderam ao terceiro ciclo de pastejo, à exceção da altura do dossel, que ocorreu no $2^{\underline{0}}$ ciclo. O momento de pastejo teve efeito sobre todas as características estudadas, cujos valores foram mais altos à entrada dos animais, à exceção da massa de colmo. A OF decresceu durante o período de pastejo, alcançando valor mínimo de 10,6\% do peso vivo. O ganho diário médio atingiu valores de 824 e $760 \mathrm{~g} / \mathrm{nov}$./dia, respectivamente, em piquetes sob os períodos de descanso de 2,5 e 3,5 novas folhas/perfilho, que apresentaram taxa de lotação de 3,65 e 3,53 novilhos/ha e ganhos de peso vivo em torno de 433 e 371 kg/ha.
\end{abstract}

Palavras-chave: altura, massa de colmo, massa de forragem, relação folha/colmo

\section{Rest Period, Canopy Structural Traits and Steer Body Weight Gain on Intermittently Grazed Mombaçagrass Pasture}

\begin{abstract}
It was evaluated the effect of two rest periods (RPs) on the canopy structural characteristics of paddocks of Mombaçagrass, a cultivar of Panicum maximum, under intermittent grazing; animal production was also evaluated. The RPs were defined by the time required for the expansion of 2.5 and 3.5 new leaves per tiller. Canopy traits response variables were: height, total green forage mass (TGFM), green leaf mass (GLM), culm mass (CM), leaf/stem ratio (L/S), and leaf area index (LAI). It was also assessed the effect of the grazing cycles $\left(1^{\text {rst }}, 2^{\text {nd }}\right.$ and $3^{\text {rd }}$ cycles) and grazing time (first and last grazing days) on these same variables as well as on forage allowance (FA). The experimental area was divided into six and seven paddocks for the experimental treatments of 2.5 and 3.5 new leaves per tiller, respectively. The experimental design was a completely randomized with two replications. The assessed structural traits were not affected by rest period, except the leaf/stem ratio. The L/S ratio was wider in the paddocks under the shorter RP but only on the first day of the grazing period and declined with the succession of the grazing cycles. The assessed structural traits figures increased as the grazing cycles succeeded each other except the CM. Reflecting the selective grazing, all structural traits figures declined over the grazing period except the CM. The FA decreased over the grazing period reaching the value of $10.6 \%$ live weight on the last grazing day. Live weight gain averaged 824 and $760 \mathrm{~g} /$ day/steer and animal productivities averaged 473 and $371 \mathrm{~kg} / \mathrm{ha}$, for the 2.5 and 3.5 new leaves/tiller rest period treatments, respectively, with average stocking rate of 3.6 steers/ha.
\end{abstract}

Key Words: culm mass, forage mass, height, leaf / stem ratio

\section{Introdução}

A produtividade animal das pastagens tropicais é baixa, de aproximadamente $150 \mathrm{~kg} / \mathrm{ha} /$ ano (Corsi \&
Aguiar, 2003), mas pode ser melhorada pelo aumento do ganho de peso individual e, principalmente, pelo incremento de suas capacidades de suporte.

Entre as opções mais viáveis para aumentar a

\footnotetext{
${ }^{1}$ Parte da tese do primeiro autor; pesquisa financiada pela FAPEMIG.

${ }^{2}$ Professor Adjunto de Nutrição e Pastagem do Departamento de Agronomia, Universidade Federal de Rondônia, Campus de Rolim de Moura, Avenida Norte Sul, 7300, Bairro Nova Morada, Rolim de Moura, Rondônia, CEP: 78987-000

${ }^{3}$ Engenheiro Agrônomo, pesquisador Embrapa - CNPGL - Juiz de Fora-MG.

${ }^{4}$ Professor Adjunto, Departamento de Zootecnia, Universidade Federal do Ceará, Av. Mister Hull, 2977, Campus Universitário do Picí, Fortaleza-CE,60970-355, TEL: (85)4008-9711, FAX: (85)4008-9701 (mjdcandido@gmail.com).

${ }^{5}$ Bolsista do CNPq (jagomide@ufv.br).
} 
produtividade e a eficiência dos sistemas de produção, Euclides et al. (1999) destacam o cultivo de espécies forrageiras mais produtivas, a adubação nitrogenada e o controle da utilização das pastagens pela manipulação da taxa de lotação e/ou do método de pastejo.

As gramíneas do gênero Panicum se destacam como as mais produtivas e ocupam o segundo lugar no mercado de sementes no país. Nos últimos 20 anos, foram lançados nove cultivares, entre eles o Centenário, em 1988, o Vencedor, em 1990, o Tanzânia, em 1990 e o Mombaça, em 1993 (Jank, 1994).

O desempenho animal é condicionado, entre vários fatores, pelo consumo de forragem, fortemente condicionado pela estrutura do dossel forrageiro, pela oferta de forragem e pelo seu valor nutritivo. As principais características estruturais do dossel forrageiro que condicionam o comportamento ingestivo do ruminante em pastejo são a biomassa vegetal, a altura do dossel, a presença de material morto e a relação folha/colmo (Chacon \& Stobbs, 1976; Euclides et al., 1999).

As gramíneas tropicais, ao contrário das temperadas, possuem, em sua maioria, grande diferenciação morfológica e apresentam, mesmo no estádio vegetativo, intenso alongamento das hastes (Gomide, 2001) do qual resulta o estreitamento da relação folha/ colmo (Santos et al., 1999; Gomide, 2001), característica estrutural que compromete o consumo de forragem pelo animal (Stobbs, 1973). Em pastagens tropicais, a densidade de folhas do dossel $(\mathrm{kg} \mathrm{MS} / \mathrm{ha} / \mathrm{cm})$ e sua relação folha/colmo são determinantes no consumo de forragem (Stobbs, 1973).

Portanto, entre as estratégias de manejo da pastagem, deve-se contemplar o controle do alongamento do colmo.

Sollenberger \& Burns (2001) ressaltam que, nas gramíneas $\mathrm{C}_{4}$, as características mais relevantes para o comportamento ingestivo animal são a biomassa de forragem verde ou de folhas verdes e a proporção de folhas do estrato superior do dossel.

Em razão do seu hábito de crescimento e de suas características de elevação dos meristemas apicais, de perfilhamento, intenso alongamento do colmo e de acúmulo de carboidratos não-estruturais na base do colmo, recomenda-se que as gramíneas tropicais cespitosas sejam utilizadas sob método de lotação intermitente (Rodrigues \& Reis, 1995; Gomide, 1997). Quando se decide por esse método, um dos importantes fatores de manejo é a definição do período de descanso.
O período de descanso não deve ser muito longo, a fim de se prevenir os processos que comprometem o valor nutritivo e as características estruturais do dossel. Estudos em cultivares de Panicum maximum demonstraram a capital importância do período de descanso (Santos et al., 1999; Gomide, 2001; Cândido et al. 2005a) sobre o alongamento de colmos, processo determinante da relação folha/colmo.

A definição do período de descanso com base na idade cronológica do dossel, apesar de facilitar a condução do pastejo de lotação intermitente, mostra-se, biologicamente empírica, uma vez que a morfofisiologia do dossel varia com as condições de ambiente. Entre os diversos critérios utilizados para definir o momento apropriado à entrada dos animais nos piquetes, destacam-se os conceitos de índice de área foliar (IAF) (Lawlor, 1995), interceptação da radiação incidente (Korte et al., 1982), nível de reservas orgânicas (Gomide \& Zago, 1980; Fulkerson \& Slack, 1994) e número de folhas por perfilho (Fulkerson \& Slack, 1995).

Objetivou-se neste trabalho avaliar os efeitos de dois períodos de descanso (definidos conforme o número de folhas expandidas), dos ciclos de pastejo e do momento de pastejo sobre as características estruturais do dossel da pastagem do capim-mombaça (Panicum maximum, Jacques) e sobre o desempenho e a produtividade animal.

\section{Material e Métodos}

Na Central de Experimentação, Pesquisa e Extensão do Triângulo Mineiro (CEPET), localizada no município de Capinópolis, MG, situada a 18²41' de latitude sul e $49^{\circ} 34^{\prime}$ de longitude oeste, foi conduzido um experimento para o estudo dos efeitos de dois períodos de descanso em piquetes de capim-mombaça sob pastejo de lotação intermitente sobre as características estruturais do dossel e o ganho de peso de novilhos.

Os períodos de descanso corresponderam ao tempo necessário à expansão de 2,5 e 3,5 novas folhas por perfilho, após cinco a seis dias de pastejo, realizado por um grupo de cinco novilhos mestiços Holandês/ Zebu, com peso vivo inicial de 264,4 $\pm 11 \mathrm{~kg}$. Novilhos extras, em número variável, foram introduzidos em cada piquete, conforme a biomassa de forragem à entrada dos animais experimentais, de modo a se obter, ao final do período de pastejo, oferta de forragem de $10 \%$ (10 kg MS/100 kgPV/dia). 
As condições de ambiente, durante todo o período experimental, foram registradas em estação meteorológica, instalada a $50 \mathrm{~m}$ da área experimental.

Da área experimental (6 ha), foram separados 2,53 ha, divididos em 13 piquetes, dos quais seis, com área de $2.350 \mathrm{~m}^{2}$, foram sorteados para o período de descanso de 2,5 novas folhas e os sete restantes, com área de 1.600 $\mathrm{m}^{2}$, para o período de descanso de 3,5 novas folhas por perfilho. O restante da área (3,47 ha) foi reservado para acomodar qualquer um dos dois grupos de cinco novilhos, quando necessário, além dos novilhos extras.

As características estruturais de interesse (variáveis-resposta) foram: biomassa de forragem verde (BFVT), biomassa de folhas verdes (BFV), biomassa de colmo (BC), altura do dossel, relação folha/colmo e índice de área foliar (IAF), ao início e no último dia do período de pastejo de cada ciclo de pastejo. Também foram realizadas estimativas da oferta de forragem verde e, após alguns ciclos de pastejo, da interceptação da radiação fotossinteticamente ativa.

No início do período experimental, a área dos 13 piquetes experimentais sofreu roçada mecânica, a $10 \mathrm{~cm}$ do solo, por meio de segadeira-condicionadora, após pastejo de rebaixamento da vegetação. Para o condicionamento do manejo de lotação intermitente, a roçada, iniciada em 23/10/2001, foi conduzida de forma escalonada, a cada cinco dias, de modo que, na roçada do último piquete de cada tratamento (23/11 e 28/11/2001), um grupo de cinco novilhos foi introduzido no primeiro piquete roçado, correspondente a cada período de descanso experimental. Assim, 10 novilhos castrados, mestiços Holandês-Zebu, com peso vivo médio de $264 \mathrm{~kg}$, foram sorteados para formarem dois grupos de cinco, que foram alocados por sorteio ao respectivo período de descanso.

Adubação em cobertura, com $250 \mathrm{~kg} / \mathrm{ha}$ da fórmula 20-5-20, correspondendo às doses de 50, 12,5 e $50 \mathrm{~kg} / \mathrm{ha}$ de $\mathrm{N}, \mathrm{P}_{2} \mathrm{O}_{5}$ e $\mathrm{K}_{2} \mathrm{O}$, respectivamente, foi efetuada imediatamente após a roçada mecânica de cada piquete e repetida à saída dos animais de cada piquete, após o segundo ciclo de pastejo.

Estimativas da condição dos piquetes foram realizadas em amostras da forragem, colhida em áreas delimitadas por retângulos de 1,5 m² (1,5 m x $1 \mathrm{~m})$, em pontos representativos da condição média do piquete (altura, densidade e coloração do dossel). As amostragens foram feitas à entrada e saída dos animais, em dois piquetes (repetições) de cada período de descanso, por ciclo de pastejo. Os perfilhos delimi- tados pelo retângulo foram colhidos a $20 \mathrm{~cm}$ do solo, colocados em sacos previamente identificados e levados ao laboratório para processamento.

A forragem colhida de cada retângulo foi separada em lâmina foliar verde e colmo, pesando-se cada fração separadamente. A subamostra de cada fração foi seca a $75^{\circ} \mathrm{C}$ por 72 horas, a fim de se estimar seu teor de matéria seca. Considerando-se os dados de matéria seca, estimaram-se a biomassa de forragem verde total (BFVT), de folhas verdes (BFV), de colmo (BC) e a relação folha/colmo. O índice de área foliar (IAF) foi estimado a partir de alíquotas da lâmina foliar. Para isso, uma alíquota das lâminas foliares foi cortada em segmentos de $10 \mathrm{~cm} \mathrm{e} \mathrm{o}$ somatório das larguras de todos segmentos, multiplicado por $10 \mathrm{~cm}$, estimou a área foliar da subamostra. Os segmentos (em torno de 150) foram pesados para se estimar a área foliar específica, que foi utilizada, junto com a biomassa das folhas verdes, para o cálculo da área de folhas verdes correspondente à área amostrada. O IAF foi obtido pela divisão da área foliar estimada por $1,5 \mathrm{~m}^{2}$, área amostrada.

No terceiro ciclo de pastejo, foram realizadas estimativas da interceptação da radiação fotossinteticamente ativa (IRFA), pelo sistema de análise de dossel - SUNSCAN (Delta T, Cambridge, Inglaterra), à entrada e saída dos animais em alguns piquetes. O SUNSCAN é composto por um sensor que mede a radiação fotossinteticamente ativa incidente, uma sonda com uma linha de sensores que determina a radiação que, após atravessar o dossel, atinge o nível do solo, e um coletor que registra as leituras das radiações incidente e transmitida e, a partir delas, estima a IRFA e fornece o IAF do dossel.

Ao final de cada ciclo de pastejo, foi realizada a pesagem dos animais, após aproximadamente 18 horas de jejum. O peso vivo dos novilhos foi considerado na determinação da carga animal compatível com a oferta de forragem desejada e na estimação do ganho diário de peso vivo dos animais.

A movimentação dos animais experimentais e de equilíbrio, em cada piquete, foi anotada diariamente, a fim de possibilitar a estimativa da taxa de lotação dos piquetes experimentais.

Os dados de matéria seca da biomassa de forragem verde total (BFVT), de folha verde (BFV), de colmo (BC), da relação folha/colmo, da altura do dossel e do índice de área foliar (IAF) foram submetidos à análise de variância, segundo o modelo: 
$\mathrm{Y}_{\mathrm{ijkl}}=\mathrm{K}+\mathrm{PD}_{\mathrm{i}}+\mathrm{CP}_{\mathrm{j}}+\mathrm{MPP}_{\mathrm{k}}+(\mathrm{PD} * \mathrm{CP})_{\mathrm{ij}}+$ $(\mathrm{PD} * \mathrm{MPP})_{\mathrm{ik}}+(\mathrm{CP} * \mathrm{MPP})_{\mathrm{jk}}+\left(\mathrm{PD}^{*} \mathrm{CP} * \mathrm{MPP}\right)_{\mathrm{ijk}}+\sum_{\mathrm{ijkl}}$

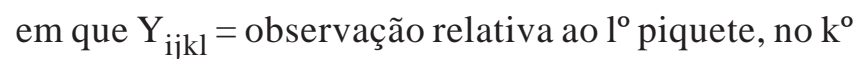
dia do período de pastejo do $\mathrm{j}^{\mathrm{o}}$ ciclo de pastejo do $\mathrm{i}^{\mathrm{o}}$ período de descanso; $\mathrm{m}$ = média da população; $\mathrm{PD}_{\mathrm{i}}=$ efeito do $\mathrm{i}^{\mathrm{o}}$ período de descanso, $\mathrm{i}=1$ e 2 períodos de descanso; $\mathrm{CP}_{\mathrm{j}}=$ efeito do $\mathrm{j}^{\mathrm{o}}$ ciclo de pastejo, j = 1무 $2 \underline{0}$ e $3^{\underline{0}}$ ciclos de pastejo; $\mathrm{MPP}_{\mathrm{k}}=$ efeito do $\mathrm{k}^{\mathrm{o}}$ dia do período de pastejo, $\mathrm{k}=1,2$ (entrada e saída dos animais); (PD.CP) $)_{\mathrm{ij}}=$ interação do $\mathrm{i}^{\circ}$ período de descanso com o j ${ }^{\circ}$ ciclo de pastejo; $(\mathrm{PD} \cdot \mathrm{MPP})_{\mathrm{ik}}=$ interação do $\mathrm{i}^{\mathrm{o}}$ período de descanso com o $\mathrm{k}^{\mathrm{o}}$ dia do período de pastejo; $(\text { CP.MPP })_{j k}=$ interação do $j^{\circ}$ ciclo de pastejo com o $\mathrm{k}^{0}$ dia do período de pastejo; (PD.CP.MPP $)_{\mathrm{ijk}}=$ interação do $\mathrm{i}^{\mathrm{o}}$ período de descanso com o j ${ }^{0}$ ciclo de pastejo e com o $\mathrm{k}^{\mathrm{o}}$ dia do período de pastejo; $\sum_{\mathrm{ijkl}}=$ efeito aleatório relativo ao $\mathrm{l}^{\circ}$ piquete, no $\mathrm{k}^{\mathrm{o}}$ dia do período de pastejo do $\mathrm{j}^{\mathrm{o}}$ ciclo de pastejo, no $\mathrm{i}^{\circ}$ período de descanso; $\mathrm{l}=1$ e 2 piquetes/ciclo de pastejo (unidades experimentais).

Quando a análise de variância indicou efeito significativo das fontes de variação, as respectivas médias foram comparadas pelo teste Tukey, a 5\% de probabilidade.

Os dados de ganho de peso médio diário (GMD) não foram submetidos à análise de variância, visto que cada grupo de cinco novilhos pastejou todos os piquetes de seu tratamento (período de descanso), não havendo, portanto, repetição "verdadeira" (Fisher,1999). Entretanto, suas estimativas médias foram comparadas àquelas relatadas por Gomide (2001) e Cândido et al (2005c), que trabalharam na mesma área e utilizaram o mesmo sistema de pastejo sob lotação intermitente nos anos agrícolas de 1999/ 2000 e 2000/2001, respectivamente.

\section{Resultados e Discussão}

Sob as condições de campo deste experimento, o intervalo de tempo para a constatação do número de novas folhas expandidas que definia o momento de entrada dos animais em cada piquete variou de 24,7 a 38,8 e de 29,9 a 46,9 dias, respectivamente, para os tratamentos 2,5 e 3,5 folhas/perfilho (Tabela 1), correspondendo a intervalos de 9,9 a 15,5 dias e de 8,5 a 13,4 dias, respectivamente, para o aparecimento de nova folha. Neste experimento, o intervalo mínimo para aparecimento de uma nova folha coincidiu com a estimativa média de 10 dias relatada por Gomide \& Gomide (2000) para este cultivar em condições de vaso, em casa de vegetação. Entretanto, intervalos mais longos também foram observados. A mesma discrepância também foi constatada por Cândido et al. (2005b), que registraram intervalos de 24 a 41, 35 a 52 e 44 a 63 dias, respectivamente, para o aparecimento de 2,5; 3,5 e 4,5 folhas/perfilho. Aparentemente, a precipitação pluvial foi o fator ambiente determinante do intervalo de tempo para o aparecimento de folhas em perfilhos de capim-mombaça durante o período experimental, visto que a temperatura mínima semanal manteve-se acima dos $20^{\circ} \mathrm{C}$ ao longo de quase todo o período experimental, não se observando variação substancial da insolação e radiação solar ao longo dos diferentes ciclos de pastejo que justificasse a variação observada no período de descanso (dados não apresentados).

Em razão dos mais longos intervalos de aparecimento de folhas, os períodos de descanso tiveram duração mais longa que a antecipada, obrigando o uso mais freqüente da área de reserva para acomodação dos animais experimentais, até que o primeiro piquete de cada ciclo de pastejo apresentasse sua condição prevista de 2,5 ou 3,5 novas folhas por perfilho. Isso ocorreu principalmente com os animais do tratamento do período de descanso de 3,5 folhas/perfilho, que, por isso mesmo, resultou em apenas três ciclos de pastejo (Tabela 1). Esta realidade reflete o condicionamento do crescimento da gramínea às condições de ambiente.

Um dos problemas para o sucesso do método de lotação intermitente é a não-coincidência de condições favoráveis de ambiente com o momento de adubação dos piquetes, o que compromete os efeitos do fertilizante aplicado. A precipitação pluvial mostrou-se satisfatória ao longo do período de adubação dos piquetes, com ocorrência de chuvas de 180 e $396 \mathrm{~mm}$ na primeira (de 24/10/2001 a 05/12/2001) e segunda adubações (08/01/2002 a 01/03/2002), respectivamente.

A análise de variância dos dados relativos às características estruturais do dossel e à oferta de forragem (OF) revelou significância $(\mathrm{P}<0,05)$ apenas dos efeitos principais dos fatores estudados: período de descanso, ciclo e momento de pastejo, à exceção da relação folha/colmo, que também sofreu efeito da interação destes fatores. Assim, os valores das Tabelas 2 e 3 não indicam condição de pré-pastejo, visto que representam estimativas médias de repetição e dos outros dois fatores delas excluídos. 
Tabela 1 - Duração dos períodos de pastejo, de descanso (PD) e de uso da área de reserva e número de folhas por perfilho no momento de entrada dos animais nos piquetes, por ciclo de pastejo

Table 1 - Lenght of the grazing and rest periods (RP), number of days of use of reserve área, and leaf number per tiller in experimental paddocks per grazing cycle

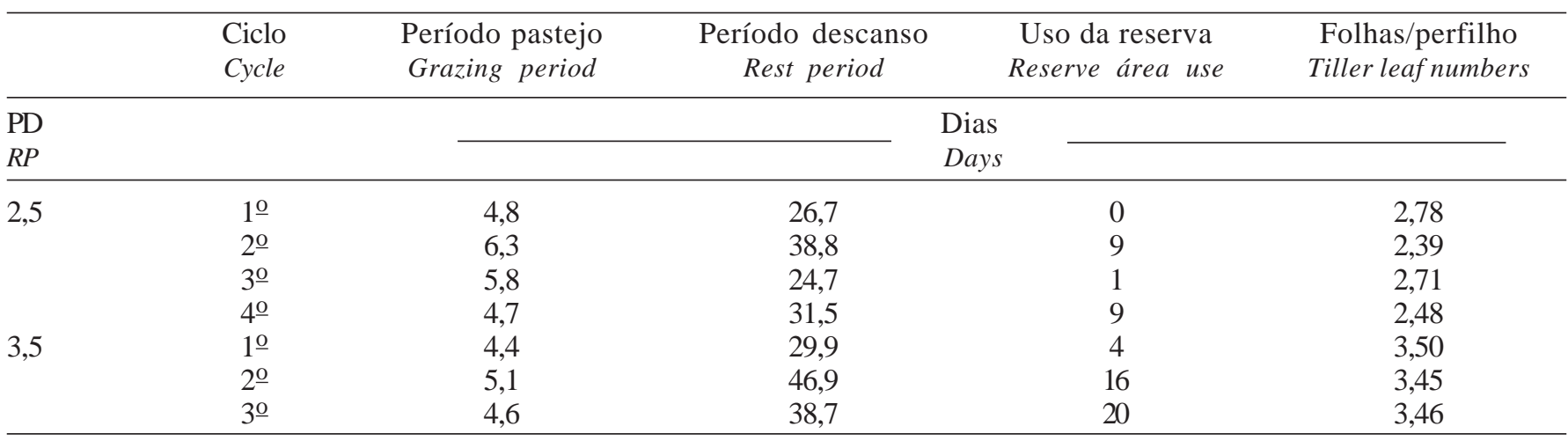

As estimativas médias da altura do dossel, das massas de folha e de colmo, da massa total, do IAF e da oferta de folhas, de acordo com os períodos de descanso, são apresentadas na Tabela 2. Verificouse efeito significativo do período de descanso apenas sobre a oferta de forragem, com menor valor para o período de descanso de 3,5 novas folhas.

A altura média do dossel do piquete pastejado após aparecimento de 2,5 novas folhas/perfilho (Tabela 2), estimada considerando-se todos os ciclos e períodos de pastejo, se aproximou bastante daquela registrada por Cândido et al. (2005b), de 55,9 cm, na mesma área e sob mesmo manejo deste experimento, no ano agrícola de 2000/2001. Contudo, esses autores verificaram que a altura do dossel se elevou $(\mathrm{P}<0,05)$ para $72,5 \mathrm{~cm}$ em piquetes sob períodos de descanso de 3,5 novas folhas/perfilho, como resultado do mais intenso alongamento do colmo.

Neste estudo, não se constatou efeito do período de descanso $(\mathrm{P}>0,05)$ sobre a estimativa da biomassa de colmo, evidenciando a pequena intensificação do alongamento do colmo, em resposta ao prolongamento do período de descanso de 2,5 para 3,5 novas folhas/perfilho. Segundo Cândido et al. (2005a), o processo de alongamento do colmo se intensificou após o dossel atingir IAF crítico, interceptando $95 \%$ da luz, valor alcançado neste experimento entre a condição de 2,5 a 3,5 novas folhas/perfilho. As interceptações da radiação fotossinteticamente ativa no momento de entrada dos animais nos piquetes nete experimento foram, em média, de 85 e 89\%, respectivamente, nos piquetes sob pastejo com período de descanso de 2,5 e 3,5 novas folhas/perfilho.
Os valores médios de índice de área foliar (Tabela 2) também foram inferiores aos encontrados por Gomide (2001), que relatou médias de 9,1 e 8,9 na condição de pré-pastejo, para os períodos de 2,5 e 3,5 novas folhas/perfilho, respectivamente, também sem efeito dos períodos de descanso.

Os períodos de descanso não afetaram a média da biomassa de forragem verde total (Tabela 2), diferentemente dos resultados obtidos nos anos agrícolas de 1999/2000 (Gomide, 2001) e 2000/2001 (Candido et al., 2005b), em que a biomassa de forragem verde cresceu com o período de descanso do piquete. Santos et al. (1999) também verificaram esse comportamento para os cultivares Mombaça e Tanzânia, com incremento na produção de forragem como resposta ao aumento do período de descanso de 28, 38 e 48 dias. Normalmente, o acréscimo na biomassa em resposta aos aumentos do intervalo de pastejo decorre, principalmente, do incremento em biomassa de colmo, fenômeno praticamente não manifestado neste experimento (Tabela 2).

Apenas no primeiro ciclo de pastejo, Gomide (2001) e Cândido et al. (2005b) não verificaram efeito significativo do período de descanso sobre a biomassa de forragem, ao compararem os intervalos de 2,5 e 3,5 novas folhas/perfilho. Neste experimento, a ausência de efeito $(\mathrm{P}>0,05)$ sobre a biomassa de forragem, que não se limitou ao primeiro ciclo de pastejo, pode ser atribuída à pequena diferença na duração dos períodos de descansos estudados, em média 30 e 38,5 dias, respectivamente, para os períodos de 2,5 e 3,5 novas folhas/perfilho, mas, principalmente, ao pequeno acúmulo de colmo na forragem sob período de descanso mais longo. 
Tabela 2 - Valores médios das características estruturais do dossel e da oferta de forragem em função do período de descanso

Table 2 - Mean values of canopy structural traits and forage allowance as a function of the rest period

\begin{tabular}{|c|c|c|c|c|}
\hline \multirow[t]{2}{*}{$\begin{array}{l}\text { Variável } \\
\text { Variable }\end{array}$} & \multicolumn{2}{|c|}{$\begin{array}{l}\text { Período de descanso } \\
\text { Rest period }\end{array}$} & \multirow[b]{2}{*}{ dms } & \multirow[b]{2}{*}{$\begin{array}{l}\text { Média } \\
\text { Mean }\end{array}$} \\
\hline & $\begin{array}{l}\text { 2,5 folhas/perfilho } \\
2.5 \text { (leaves/tiller) }\end{array}$ & $\begin{array}{l}\text { 3,5 folhas/perfilho } \\
\text { 3.5 leaves/tiller }\end{array}$ & & \\
\hline \multicolumn{5}{|l|}{ Altura (cm) } \\
\hline Height & $(53,2) 54,7 \mathrm{~A}$ & $59,3 \mathrm{~A}$ & 6,8 & 57 \\
\hline $\begin{array}{l}\text { BFVT (kg MS/ha) } \\
\text { GFM (kg DM/ha) }\end{array}$ & (1748) $1794 \mathrm{~A}$ & $1952 \mathrm{~A}$ & 587 & 1873 \\
\hline BFV (kg MS/ha) & (1398) $1477 \mathrm{~A}$ & $1476 \mathrm{~A}$ & 364 & 1476 \\
\hline $\begin{array}{l}\text { GLM (kg DM/ha) } \\
\text { BC (kg MS/ha) } \\
C M(\mathrm{~kg} \mathrm{DM} / \mathrm{ha})\end{array}$ & (351) $317 \mathrm{~A}$ & $476 \mathrm{~A}$ & 259 & 396 \\
\hline \multicolumn{5}{|l|}{ IAF } \\
\hline$L A I$ & $(2,65) 2,80 \mathrm{~A}$ & 2,86 A & 0,62 & 2,83 \\
\hline $\begin{array}{l}\text { OF (kg BFV/100 kg PV/dia) } \\
F A(k g \text { GFM100 kg BW/day) }\end{array}$ & $(18,8) 20,0 \mathrm{~A}$ & 14,6 B & 4,00 & 17,30 \\
\hline
\end{tabular}

$\mathrm{BFVT}=$ biomassa de forragem verde total; $\mathrm{BFV}=$ biomassa de folhas verdes; $\mathrm{BC}=$ biomassa de colmo.

GFM = total green forage biomass; GLM = green leaf biomass; $C M=$ culm biomass.

Valores entre parênteses correspondem à média de quatro ciclos de pastejo. Médias seguidas de letras distintas diferem $(P<0,05)$ pelo teste Tukey. dms = diferença mínima significativa.

Figures in parentheses stand for the means from four grazing cycles. Means with different letters differ $(P>0.05)$ by Tukey test; Isd=least significant difference.

A estimativa média geral da biomassa total de forragem verde (Tabela 2) foi bem inferior às da forragem verde pré-pastejo nos anos agrícolas de 1999/2000 (4571 e 5584 kg/ha) e 2000/2001 (3904 e 6511 kg/ha), relatadas por Gomide (2001) e Cândido et al. (2005b), respectivamente. Ressalta-se que, neste caso, os valores de biomassa de forragem não se referem à condição de pré-pastejo, mas às médias envolvendo ciclos e períodos de pastejo.

Essa discrepância poderia ser atribuída a um possível esgotamento da fertilidade do solo da área. Entretanto, a análise do solo revelou incremento em K com o suceder dos anos agrícola e concentrações de $\mathrm{Ca}+\mathrm{Mg}$ que atendem ao requerimento de $1,5 \mathrm{cmol}_{c} / \mathrm{dm}^{3}$ (dados não apresentados), sugerido para o capim-mombaça (Comissão de Fertilidade do Solo de MG, 1999 - 5 Aproximação), enquanto os teores de $\mathrm{P}$, um dos nutrientes mais importantes relacionados à persistência da pastagem, se situaram entre 6 e $10 \mathrm{mg} / \mathrm{dm}^{3}$ Assim, não parece haver problemas de fertilidade do solo. De fato, a produção de biomassa no terceiro ciclo de pastejo, sob ambos os tratamentos, resultante de rebrotação antecedida da mesma adubação inicial, mas sob condições mais favoráveis de pluviosidade (396 mm de chuva) no período de 08/01 a 01/03/2002, evidencia que a fertilidade do solo não foi o fator condicionante do baixo acúmulo de biomassa nos dois primeiros ciclos de pastejo. No terceiro ciclo, as massas de forragem pré- pastejo, de 3296 e 3396 kg/ha, para o menor e maior períodos de descanso, respectivamente, foram próximos aos valores encontrados nos anos agrícolas anteriores para o período de descanso de 2,5 novas folhas por perfilho. Diferentemente dos períodos de descanso, os ciclos de pastejo influenciaram a maioria das características estruturais do dossel.

Os valores das estimativas médias de altura do dossel, das biomassas de folha e de colmo, de biomassa total, do IAF e de oferta de folhas, de acordo com os ciclos de pastejo, encontram-se na Tabela 3.

Todas as características estruturais cresceram com a sucessão dos ciclos de pastejo, com os maiores valores correspondendo ao terceiro ciclo de pastejo (Tabela 3). A altura do dossel, tanto à entrada como à saída dos animais do piquete, tendeu a se elevar com o suceder dos ciclos de pastejo (dados não apresentados), o que expõe a limitação da altura do dossel como critério para orientar a movimentação dos animais entre os piquetes, sob condições que favorecem o processo de alongamento do colmo. Cândido et al. (2005b) concluiu que o tratamento de 2,5 folhas/ perfilho propiciou razoável controle da altura do dossel no momento de entrada dos animais nos piquetes. Neste trabalho, esse controle foi observado também para o período de descanso de 3,5 novas folhas/ perfilho, em razão do limitado processo de alongamento do colmo. 
Tabela 3 - Valores médios das características estruturais do dossel, de acordo com o ciclo de pastejo Table 3 - Mean values of canopy structural traits as a function of the grazing cycles

\begin{tabular}{|c|c|c|c|c|c|}
\hline \multirow[t]{2}{*}{$\begin{array}{l}\text { Variável } \\
\text { Variable }\end{array}$} & \multicolumn{3}{|c|}{$\begin{array}{l}\text { Ciclo de pastejo } \\
\text { Grazing cycle }\end{array}$} & \multirow[t]{2}{*}{$\begin{array}{l}\mathrm{dms} \\
\text { lsd }\end{array}$} & \multirow[t]{2}{*}{$\begin{array}{l}\text { Média } \\
\text { Mean }\end{array}$} \\
\hline & $1^{\underline{0}}\left(1^{s t}\right)$ & $2^{-0}\left(2^{\text {nd }}\right)$ & $3^{-} \underline{(}\left(3^{r d}\right)$ & & \\
\hline $\begin{array}{l}\text { Altura (cm) } \\
\text { Heiaht }\end{array}$ & $45,4 \mathrm{~B}$ & $60 \mathrm{~A}$ & $65,6 \mathrm{~A}$ & 10,2 & 57 \\
\hline $\begin{array}{l}\text { Height } \\
\text { BFVT (kg MS/ha) } \\
\text { GFM }\end{array}$ & $1272 B$ & 1673B & $2673 A$ & 880 & 1873 \\
\hline $\begin{array}{l}\text { BFV (kg MS/ha) } \\
\text { GLM }\end{array}$ & 1191B & 1352B & $1884 \mathrm{~A}$ & 545 & 1476 \\
\hline $\begin{array}{l}\text { BC (kg MS/ha) } \\
C M\end{array}$ & $81 \mathrm{~B}$ & $320 \mathrm{~B}$ & $788 \mathrm{~A}$ & 389 & 396 \\
\hline $\begin{array}{l}\text { IAF } \\
L A I\end{array}$ & $2,60 \mathrm{~B}$ & $2,19 \mathrm{~B}$ & $3,71 \mathrm{~A}$ & 0,94 & 2,83 \\
\hline
\end{tabular}

Médias seguidas de letras distintas, diferem $(P<0,05)$ pelo teste Tukey; dms corresponde à diferença mínima significativa. Means with same letter do not differ $(P>0.05)$ by Tukey test; Isd stand for least significance difference.

Progressivos incrementos de biomassa de folha, de forragem verde total e, principalmente, de colmo foram observados a cada ciclo de pastejo (Tabela 3). Esse comportamento, característico do sistema sob lotação intermitente, resulta do incremento de resíduo de forragem a cada ciclo de pastejo, decorrente do pastejo seletivo exercido pelo animal, que propicia acúmulo de colmo. Neste estudo, o incremento de colmo do segundo para o terceiro ciclo alcançou, percentualmente, quase o quádruplo do incremento percentual de folha.

O IAF apresentou a mesma tendência da massa de forragem, em razão de ele se relacionar diretamente à massa de folhas (Tabela 3). Verificou-se maior valor de IAF no terceiro ciclo de pastejo, o que, provavelmente foi um reflexo benéfico da segunda adubação de manutenção.

Não se verificou efeito dos ciclos de pastejo sobre a oferta de forragem, que variou de 15,1 a 20,0\%PV/dia, com média de 17,3\%PV/dia, em razão do ajuste da carga animal conforme a biomassa de forragem do piquete.

As alturas pré-pastejo do dossel (Tabela 4) se situaram abaixo das médias observadas no ano agrícola de 1999/2000 (Gomide, 2001), discrepância atribuída ao menor crescimento da forrageira neste experimento. Isso pode ser comprovado pela avaliação da massa seca de forragem apresentada por Gomide (2001), de 4.571 e $5.584 \mathrm{kgMS} / \mathrm{ha} /$ ciclo de pastejo, respectivamente, para os tratamentos 2,5 e 3,5 folhas/perfilho. Neste estudo, no momento de entrada dos animais, a massa média de forragem, à entrada dos novilhos nos piquetes, foi de $2.451 \mathrm{kgMS} / \mathrm{ha} /$ ciclo (Tabela 4). A discrepância é atribuível principalmente às diferenças de pluviosidade entre os anos agrícolas. Ressalta-se a acentuada variação das características estruturais do dossel durante o período de pastejo, ao final do qual todas as características avaliadas, à exceção da biomassa de colmo, proporcionaram estimativas inferiores àquelas do momento de entrada (Tabela 4). Embora diminuições de biomassa de forragem total e de folhas tenham sido constatadas, os valores de biomassa de colmo se mantiveram constantes, com tendência de aumento ao longo do período de pastejo.

Esse comportamento, característico do sistema de lotação intermitente, primeiramente registrado por Chacon \& Stobbs (1976) em gramíneas tropicais, sinaliza a importância de se reduzir a taxa de lotação do piquete no decorrer do período de pastejo ou, alternativamente, reduzir sua duração para não comprometer o desempenho animal nos últimos dias do período de pastejo.

O IAF observado no momento de entrada dos animais foi bem inferior ao valor médio de 9,0, relativo ao ano agrícola de 1999/2000 (Gomide, 2001). As prováveis causas para esta discrepância foram abordadas quando se discutiu a biomassa de forragem. Apesar dos mais baixos valores de IAF no pré-pastejo, a interceptação da radiação fotossinteticamente ativa avaliada para o terceiro ciclo de pastejo $(91,6 \%)$ foi bem próxima aos valores médios de $96 \%$, encontrado por Gomide (2001), e de 90 e 96\%, registrados por Candido et al. (2005c) para os tratamentos 2,5 e 3,5 folhas/perfilho no momento de entrada dos animais nos piquetes. Esses resultados evidenciam a grande adaptação morfológica do dossel do capim-mombaça, propiciando eficiente interceptação da radiação 
Tabela 4 - Valores médios das características estruturais do dossel e da oferta de forragem de acordo com o momento de pastejo

Table 4 - Mean values of canopy structural traits and forage allowance as a function of grazing time

\begin{tabular}{|c|c|c|c|c|c|}
\hline \multirow[t]{2}{*}{$\begin{array}{l}\text { Variável } \\
\text { Variable }\end{array}$} & \multicolumn{3}{|c|}{$\begin{array}{l}\text { Momento de pastejo } \\
\text { Grazing time }\end{array}$} & \multirow[t]{2}{*}{$\begin{array}{l}\text { Dms } \\
\text { lsd }\end{array}$} & \multirow[t]{2}{*}{$\begin{array}{l}\text { Média } \\
\text { Mean }\end{array}$} \\
\hline & $\begin{array}{l}\text { Início } \\
\text { Start }\end{array}$ & $\begin{array}{l}\text { Meio } \\
\text { Midle }\end{array}$ & $\begin{array}{l}\text { Final } \\
\text { End }\end{array}$ & & \\
\hline $\begin{array}{l}\text { Altura }(\mathrm{cm}) \\
\text { Height }\end{array}$ & $74,3 \mathrm{~A}$ & $(47,5)$ & 39,7B & 6,8 & 57 \\
\hline $\begin{array}{l}\text { BFVT (kg MS/ha) } \\
\text { GFM (kg DM/ha) }\end{array}$ & $2.451 \mathrm{~A}$ & (1.602) & $1.294 \mathrm{~B}$ & 587 & 1873 \\
\hline $\begin{array}{l}\text { BFV (kg MS/ha) } \\
\text { GLM (kg DM/ha) }\end{array}$ & $2.093 \mathrm{~A}$ & (1.224) & 859B & 364 & 1476 \\
\hline $\begin{array}{l}\mathrm{BC}(\mathrm{kg} \mathrm{MS} / \mathrm{ha}) \\
C M(\mathrm{~kg} \mathrm{DM} / \mathrm{ha})\end{array}$ & $358 \mathrm{~A}$ & (377) & $435 \mathrm{~A}$ & 259 & 396 \\
\hline $\begin{array}{l}\text { IAF } \\
\text { LAI }\end{array}$ & $4,17 \mathrm{~A}$ & $(2,79)$ & 1,50B & 0,62 & 2,83 \\
\hline $\begin{array}{l}\mathrm{OF}(\% \mathrm{PV} / \text { dia }) \\
\text { FA (\%LW/day) }\end{array}$ & $24,0 \mathrm{~A}$ & $(18,1)$ & $10,6 \mathrm{~B}$ & 4,00 & 17,30 \\
\hline
\end{tabular}

Médias seguidas de letras distintas diferem $(P<0,05)$ pelo teste Tukey; dms = diferença mínima significativa. Os valores entre parênteses correspondem a estimativas a partir de número variável de repetições conforme o ciclo de pastejo.

Averages followed by same letter do not differ by the Tukey test $(P>0.05)$; Isd=least significant difference. Figures within parentheses stand for the estimates from variable number of repetition according to grazing cycle.

fotossinteticamente ativa sob diversas condições de características estruturais (Alexandrino et al., 2005).

A oferta de forragem, composta basicamente por folhas no início do período de pastejo, decresceu de $24 \%$, no primeiro dia de pastejo, alcançando valor próximo ao desejado, de $10 \%$, ao final do período de pastejo.

A relação folha/colmo foi a única característica estrutural estudada que sofreu efeito da interação dos fatores período de descanso, ciclo e momento de pastejo.

Largas relações folha/colmo foram observadas à entrada dos animais no piquete (Tabela 5), bem superiores àquelas de 4,6 e 3,7 apresentadas por Gomide (2001). Essa forte discrepância, em parte atribuível às diferenças nas alturas de colheita da forrageira, devese sobretudo à pequena biomassa de colmo neste experimento, visto que se trata de uma relação cuja magnitude foi determinada pelo seu denominador, neste caso, a baixa biomassa de colmo.

A relação folha/colmo diminuiu com o prolongamento do período de descanso, a sucessão dos ciclos de pastejo e o decurso do período de pastejo (Tabela 5), como conseqüência da progressiva desfolha do dossel ocasionada pelo pastejo seletivo praticado pelos animais (Chacon \& Stobbs, 1976).

No momento da entrada dos animais nos piquetes, a relação folha/colmo foi significativamente mais larga no dossel submetido ao menor período de descanso (Tabela 5), uma situação desejável, pois é uma característica estrutural do dossel que favorece o consumo animal (Stobbs, 1973). Entretanto, em razão do pastejo seletivo dos novilhos, não variou com o período de descanso, ao final do período de pastejo.

Os ciclos de pastejo tiveram grande efeito sobre a relação folha/colmo, observando-se acentuado estreitamento dessa variável no decorrer dos ciclos, principalmente nos piquetes sob menor período de descanso. A redução gradativa na relação folha/ colmo com o aumento do período de descanso e a sucessão dos ciclos de pastejo normalmente decorre do acúmulo de colmo, observado por Cândido et al. (2005c), em virtude do contínuo alongamento do colmo e da preferência dos animais em consumir folhas do dossel.

Avaliando em conjunto o período de descanso e o ciclo de pastejo, verifica-se mais larga relação folha/ colmo apenas no primeiro ciclo de pastejo, evidenciando o forte efeito dos ciclos de pastejo sobre o acúmulo de hastes e, portanto, sobre a relação folha/ colmo. Esses resultados corroboram aqueles obtidos por Cândido et al. (2005c), que demonstraram o efeito negativo do longo período de descanso e dos ciclos de pastejo sobre a relação folha/colmo. A relação folha/ colmo tende a ser superior em piquetes submetidos a curtos períodos de descanso, embora a significância das diferenças tenha se restringido ao primeiro ciclo de pastejo. 
Tabela 5 - Valores médios da relação folha/colmo de acordo com as interações período de descanso x dia do período de pastejo, período de descanso x ciclos de pastejo e dia do período de pastejo x ciclos de pastejo

Table 5 - Mean values for leaf/stem ratio as a function of the interactions: rest period $x$ day of grazing period, rest period $x$ grazing cycle and day of grazing period $x$ grazing cycle

\begin{tabular}{|c|c|c|c|c|c|}
\hline \multirow[t]{2}{*}{$\begin{array}{l}\text { Dia de pastejo } \\
\text { Grazing day }\end{array}$} & \multicolumn{3}{|c|}{$\begin{array}{l}\text { Período de descanso } \\
\text { Rest period }\end{array}$} & \multirow[b]{2}{*}{$\mathrm{dms}$} & \multirow[b]{2}{*}{$\begin{array}{l}\text { Média } \\
\text { Average }\end{array}$} \\
\hline & $\begin{array}{l}\text { 2,5 folhas/perfilho } \\
2.5 \text { (leaves/tiller) }\end{array}$ & \multicolumn{2}{|c|}{$\begin{array}{l}\text { 3,5 folhas/perfilho } \\
\text { 3.5 leaves/tiller }\end{array}$} & & \\
\hline Primeiro (First) & 48,5Аа & \multicolumn{2}{|c|}{$16,7 \mathrm{Ab}$} & 12,6 & 32,6 \\
\hline Terceiro (Third) & $(7,4)$ & \multirow{2}{*}{\multicolumn{2}{|c|}{$\begin{array}{c}(4,2) \\
5,2 \mathrm{Aa}\end{array}$}} & & $(5,8)$ \\
\hline Ultimo (Last) & $4,6 \mathrm{Ba}$ & & & & 4,9 \\
\hline Dms (Lsd) & 12,6 & & & & \\
\hline Média (Average) & 26,6 & \multicolumn{2}{|c|}{11,0} & & 18,8 \\
\hline \multirow[t]{2}{*}{$\begin{array}{l}\text { Ciclo de pastejo } \\
\text { Grazing time }\end{array}$} & \multicolumn{3}{|c|}{$\begin{array}{l}\text { Período de descanso } \\
\text { Rest period }\end{array}$} & \multirow[b]{2}{*}{ dms } & \multirow[b]{2}{*}{$\begin{array}{l}\text { Média } \\
\text { Average }\end{array}$} \\
\hline & $\begin{array}{c}2,5 \text { folhas/perfilho } \\
2.5 \text { (leaves/tiller) }\end{array}$ & \multicolumn{2}{|c|}{$\begin{array}{c}\text { 3,5 folhas/perfilho } \\
\text { 3.5 leaves/tiller }\end{array}$} & & \\
\hline $1^{0} \underline{0}\left(1^{s t}\right)$ & 62,3Аа & & & 15,4 & 44,3 \\
\hline $2^{\underline{o}}\left(2^{n d}\right)$ & $14,3 \mathrm{Ba}$ & & & & 9,1 \\
\hline $3^{0}\left(3^{r d}\right)$ & 3,1Ba & & & & 2,9 \\
\hline Dms (Lsd) & 18,9 & & & & \\
\hline Média (Average) & 26,6 & & & & 18,8 \\
\hline \multirow{4}{*}{$\begin{array}{l}\text { Ciclo de pastejo } \\
\text { Grazing time }\end{array}$} & \multirow{2}{*}{\multicolumn{3}{|c|}{$\begin{array}{l}\text { Momento de pastejo } \\
\text { Grazing time }\end{array}$}} & \multirow{4}{*}{$\begin{array}{c}\text { Dms } \\
l s d\end{array}$} & \multirow{4}{*}{$\begin{array}{l}\text { Média } \\
\text { Mean }\end{array}$} \\
\hline & & & & & \\
\hline & Início & Meio & Final & & \\
\hline & Start & Midle & End & & \\
\hline $1^{\underline{o}}\left(1^{s t}\right)$ & 77,9Аа & $(10,1)$ & $10,7 \mathrm{Ab}$ & 15,4 & 44,3 \\
\hline $2^{o}\left(2^{n d}\right)$ & 15,9Ba & $(4,3)$ & $2,4 \mathrm{Aa}$ & 9,1 & \\
\hline $3^{0}\left(3^{r d}\right)$ & $4,2 \mathrm{Ba}$ & $(1,96)$ & $1,7 \mathrm{Aa}$ & 2,9 & \\
\hline Dms (Lsd) & 18,9 & & & & \\
\hline Média (Average) & 26,6 & & 11,0 & 18,8 & \\
\hline
\end{tabular}

Médias seguidas de mesma letra, maiúscula (coluna) e minúscula (linha) não diferem $(P>0,05)$ pelo teste Tukey. Dms = diferença mínima significativa. Os valores entre parênteses não foram analisados estatisticamente em razão de o número de suas repetições variar conforme os diferentes ciclos de pastejo.

Figures followed by same letters, capital for the colunm and small letters for the line, do not differ by Tukey test (P>0.05). Averages in parentheses were not compared due to variation of their replication numbers according to the grazing cycle.

Apesar de a oferta de forragem (10\% do peso vivo) ao final do período de pastejo, exceder aproximadamente três vezes o consumo diário de forragem de 2,5\% PV (Euclides et al., 1999), observou-se que os animais demonstravam aparente desinteresse em continuar a preensão das folhas residuais no último dia do período de pastejo, em razão do difícil acesso, decorrente do íntimo contacto das folhas com o colmo, apesar da relação folha/colmo ser ainda relativamente larga (Tabela 5).

Antecipava-se melhor desempenho animal dos novilhos sob o tratamento de menor período de descanso, visto que nos anos anteriores foram encontrados incrementos de 33\% (Gomide, 2001) e 29\% (Cândido et al., 2005c) de ganho médio diário sob o tratamento de 2,5 em relação ao de 3,5 novas folhas/perfilho. Contudo, neste experimento, foi observada apenas tendência de menor ganho de peso vivo para os novilhos do tratamento de 3,5 novas folhas/perfilho (Tabela 6). A ausência de significância para a diferença entre os tratamentos reflete a semelhança das características estruturais entre os piquetes experimentais.

O ganho diário médio dos novilhos em piquetes submetidos ao menor período de descanso (Tabela 6) foi superior aos relatados por Gomide (2001) e Cândido et al. (2005c) para o mesmo tratamento, respectivamente, de 628 e $704 \mathrm{~g} / \mathrm{nov} /$ dia e, principalmente, ao de 3,5 novas folhas/perfilho, cujas médias foram de $473 \mathrm{~g} / \mathrm{nov} / \mathrm{dia}$ (Gomide, 2001) e $546 \mathrm{~g} / \mathrm{nov} / \mathrm{dia}$ 
Tabela 6 - Valores médios de oferta de forragem (\% PV/ dia), relação folha/colmo, ganho diário médio (g/nov/dia), taxa de lotação (novilhos/ha) e produção animal (kg/ha) ao longo do período experimental de 144 dias

Table 6 - Mean values for forage allowance (\%LW/day), leaf/ stem ratio, average daily gain ( $\mathrm{g} / \mathrm{steer} /$ day), stocking rate (steer/ha) and animal yield ( $\mathrm{kg} / \mathrm{ha}$ ) over experimental period of 144 days

\begin{tabular}{lccccc}
\hline $\begin{array}{l}\text { Tratamento } \\
\text { Treatment }\end{array}$ & $\begin{array}{c}\text { OFV } \\
\text { FA }\end{array}$ & $\begin{array}{c}\text { F/C } \\
\text { L/S }\end{array}$ & $\begin{array}{c}\text { GMD } \\
\text { ADG }\end{array}$ & $\begin{array}{c}\text { TL } \\
\text { SR }\end{array}$ & $\begin{array}{c}\text { Produção } \\
\text { Yield }\end{array}$ \\
\hline 2,5 & 20,0 & 26,6 & 824 & 3,65 & 433 \\
3,5 & 14,6 & 11,0 & 760 & 3,39 & 371 \\
\hline
\end{tabular}

(Cândido et al., 2005c). Estas diferenças no desempenho animal resultaram das características estruturais menos favoráveis do dossel nos dois primeiros anos de pesquisa, sobretudo a estreita relação folha/colmo.

O desempenho animal observado foi superior também àqueles relatados por Euclides et al. (1999), de 570, 615 e 635 g/nov/dia, respectivamente, para os capins mombaça, tanzânia, adubados com $50 \mathrm{~kg} / \mathrm{ha}$ de N, e Tanzânia, com 100 kg/ha de N, manejados sob lotação intermitente de 7 dias de pastejo com 35 dias de descanso. O melhor desempenho observado neste experimento seria conseqüência principalmente da mais alta percentagem de folha do dossel, que correspondeu, em média, a 76\% da massa de forragem verde total (Tabela 2 ), superior à de $44 \%$ verificada por esses autores. Contudo, em razão da menor taxa de lotação utilizada, os rendimentos por área, para o período de 144 dias, foram próximos àqueles obtidos por Euclides et al (1999), de 439, 462 e 516 kg/ha, respectivamente, para as gramíneas supracitadas.

As taxas de lotação alcançadas neste ensaio foram inferiores às encontradas na mesma área no ano agrícola de 2000/2001, de 6,2 e 7,0 nov/ha (Cândido et al., 2005c), respectivamente, para os tratamentos de 2,5 e 3,5 folhas/perfilho. Cândido et al. (2005c) verificaram produtividade animal de 546 e $478 \mathrm{kgPV} / \mathrm{ha}$, respectivamente, para os períodos de descanso de 2,5 e 3,5 novas folhas/perfilho, valores superiores aos deste experimento, de 433 e $371 \mathrm{kgPV} / \mathrm{ha}$.

\section{Conclusões}

As características estruturais: altura, biomassa de folhas verdes e de forragem verde total e IAF mostraram-se insensíveis aos efeitos dos períodos de descanso de 2,5 e 3,5 novas folhas por perfilho, porém, sensíveis aos ciclos de pastejo e, principalmente, ao momento do período de pastejo. Entretanto, a relação folha/colmo, respondeu à interação desses fatores. Em geral, a relação folha/colmo decresceu com o decorrer dos ciclos de pastejo e, principalmente, dos dias do período de pastejo

Visando prevenir intenso comprometimento das características estruturais do dossel, recomenda-se curto período de pastejo.

Os ganhos de peso vivo por novilho e por área não apresentaram diferenças substanciais atribuíveis aos períodos de descanso de 2,5 e 3,5 novas folhas por perfilho no terceiro ano de ensaio. Entretanto, nos dois anos anteriores, melhor desempenho e mais alta produção animal foram alcançados em piquetes pastejados sob período de descanso de 2,5 novas folhas por perfilho.

\section{Literatura Citada}

ALEXANDRINO, E.; GOMIDE, J.A.; GOMIDE, C.A.M. Crescimento do dossel de Panicum maximum "cv" Mombaça. Revista Brasileira de Zootecnia, v.34, n.6, p.2164-2173, 2005 (supl. 1).

CÂNDIDO, M.J.D.; ALEXANDRINO, E.; GOMIDE, J.A. Duração do período de descanso e crescimento do dossel de Panicum maxium cv. Mombaça sob lotação intermitente. Revista Brasileira de Zootecnia, v.34, n.2, p.398-405, 2005 . CÂNDIDO, M.J.D.; GOMIDE, C.A.M.; ALEXANDRINO, E., et al. Morfofisiologia do dossel de Panicum maximum cv Mombaça sob lotação intermitente com três períodos de descanso. Revista Brasileira de Zootecnia, v.34, n.2, p.406-415, 2005b.

CÂNDIDO, M.J.D.; ALEXANDRINO, E.; GOMIDE, C.A.M. et al. Período de descanso, valor nutritivo e desempenho animal em pastagem de Panicum maximum cv Mombaça sob lotação intermitente. Revista Brasileira de Zootecnia, v.34, n.5, p.1449-1458, 2005c.

CHACON, E.; STOBBS, T.H. Influence of progressive defoliation of a grass sward on the eating behaviour of cattle. Australian Journal of Agricultural Research, v.27, n.5, p.709-727, 1976.

COMISSÃO DE FERTILIDADE DO SOLO DE MINAS GERAIS - CFSMG. Recomendações para uso de corretivos e fertilizantes em Minas Gerais $-5^{\mathbf{a}}$ aproximação. Viçosa, MG: Universidade Federal de Viçosa, 1999. p.359.

CORSI, M.; AGUIAR, R.N. Sistema de manejo de pastagem e sustentabilidade. In: EVANGELISTA, A.R.; REIS, S.T.; GOMIDE, E.M. (Eds.) Forragicultura e pastagens: temas em evidência - sustentabilidade. Lavras: Universidade Federal de Lavras, 2003. p.227-267.

EUCLIDES, V.P.B.; THIAGO, L.R.L.S.; MACEDO, M.C.M. et al. Consumo voluntário de forragem de três cultivares de Panicum maximum sob pastejo. Revista Brasileira de Zootecnia, v.28, n.6, p.1177-1185, 1999.

FISHER, D.S. Defining the experimental unit in grazing trials. In: AMERICAN SOCIETY OF ANIMAL SCIENCE, 1999, Watkinsville. Proceedings... Watkinsville, 1999. p.1-5.ASAS. 
FULKERSON, W.J.; SLACK, K. Leaf number as a criterion for determining defoliation time for Lolium perenne. 1. Effect of water-soluble carbohydrates and senescence. Grass and Forage Science, v.49, n.4, p.373-377, 1994.

FULKERSON, W.J.; SLACK, K. Leaf number as a criterion for determining defoliation time for Lolium perenne. 2. Effect of defoliation frequency and height. Grass and Forage Science, v.50, n.1, p.16-20, 1995.

GOMIDE, C.A.M. Características morfofisiológicas associadas ao manejo do capim-Mombaça (Panicum maximum Jacq.). Viçosa, MG: Universidade Federal de Viçosa, 2001. 100p. Tese (Doutorado em Zootecnia) - Universidade Federal de Viçosa, 2001.

GOMIDE, C.A.M.; GOMIDE, J.A. Morfogênese de cultivares de Panicum maximum Jacq. Revista Brasileira de Zootecnia, v.29, n.2, p.341-348, 2000.

GOMIDE, J.A. O fator tempo e o número de piquetes do pastejo rotacionado. In: SIMPÓSIO SOBRE MANEJO DA PASTAGEM, 14., 1997, Piracicaba. Anais... Piracicaba: Fundação de Estudos Agrários Luiz de Queiroz, 1997. p.253-272.

GOMIDE, J.A.; ZAGO, C.P. Crescimento e recuperação do capim colonião após corte. Revista Brasileira Zootecnia, v.9, n.2, p.293-305, 1980.

JANK, L.; SAVIDAN, Y.; SOUZA, M.T. et al. Avaliação de germoplasma de Panicum maximum introduzido da África. 1. Produção forrageira. Revista da Sociedade Brasileira de Zootecnia, v.23, n.3, p.433-440, 1994.

KORTE, C.J.; WATKIN, B.R.; HARRIS, W. Use of residual leaf area index and light interception as criteria for spring-grazing management of ryegrass dominant pasture. New Zealand Journal of Agriculture Research, v.25, n.3, p.309-319, 1982.
LAWLOR, D.W. Photosynthesis, productivity and environment. Journal of Experimental Botany, v.46, Special Issue, p.1449-1461, 1995.

RODRIGUES, L.R.A.; REIS, R.A. Bases para o estabelecimento do manejo de capins do gênero Panicum. In: SIMPÓSIO SOBRE MANEJO DA PASTAGEM: O CAPIMCOLONIÃO, 12., 1995, Piracicaba. Anais... Piracicaba: Fundação de Estudos Agrários Luiz de Queiroz, 1995. p.197-218.

SANTOS, P.M.; CORSI, M.; BALSALOBRE, M.A.A. Efeito da freqüência de pastejo e da época do ano sobre a produção e a qualidade em Panicum maximum cvs. Tanzânia e Mombaça. Revista Brasileira de Zootecnia, v.28, n.2, p.244-249, 1999.

SOLLENBERG, L.E.; BURNS, J.C. Canopy characteristics, ingestive behavior and herbage intake in cultivated tropical grasslands. In: INTERNATIONAL GRASSLAND CONGRESS, 19., 2001, São Pedro. Proceedings... São Pedro: 2001. p.321-327.

STOBBS, T.H. The effect of plant structure on the intake of tropical pastures. II. Differences in sward structure, nutritive value, and bite size of animals grazing Setaria anceps and Chloris gayana at various stages of growth. Australian Journal of Agricultural Research, v. 24, n.6, p.821-829, 1973.

Recebido em: 15/01/05

Aceito em: 18/07/05 